\title{
The Cornerstone of Sustainability Strategy in Manufacturing Enterprises
}

\author{
David Opresnik, Marco Seregni, and Marco Taisch \\ Department of Management, Economics and Industrial Engineering, Politecnico di Milano, \\ Piazza Leonardo Da Vinci 32, 20133, Milano, Italy \\ \{david.opresnik, marco.seregni, marco.taisch\} @polimi.it
}

\begin{abstract}
Sustainability has already been seen to impact positively the competitive advantage of an enterprise. Nonetheless managing sustainability still too often represents a conundrum. Consequently, the aim of this article is to help managers of manufacturing enterprises to understand, from an integrative perspective, the impact of the concept of sustainability onto their enterprise, with the objective to increase their long-term success. Thus, it was first assayed, if sustainability is a strategy and what are its main characteristics. To ensure validity, we leaned on the most renowned definitions of "strategy". Secondly, an integrative framework for sustainability in manufacturing enterprises was designed, depicting the interrelations among the enterprise's core elements (strategies, tactics, operations) and also with the environment (legislature and market), while dedicating special attention the concept of "fit". The results altogether creates the cornerstone of the strategy of sustainability for manufacturing enterprises.
\end{abstract}

Keywords: sustainability, strategy, manufacturing, sustainable manufacturing.

\section{Introduction}

According to the National Association of Manufacturers, the manufacturing sector has the highest economic multiplier effect of all sectors [1]. Thus, manufacturing plays one of the key roles not only from an economic, but also from a social perspective, as it is a crucial provider of jobs. However, due to an increasing global competition, manufacturing enterprises in mature economies are facing a challenge how to grow on the long-term, while providing high quality jobs within a much stricter legislative environment then some of their peer countries. Thus, they are forced to define new sustainable but competitive growth alternatives. Namely, a single-minded focus on economic sustainability can succeed only in the short run; though, while long-term success requires all three dimensions of sustainability - economic, society and environment [2], [3]. Those three dimensions of sustainability are called the Triple Bottom Line (TBL) [4] through which an enterprise can create more long term value and achieve a higher long term competitive advantage, while encountering fewer risks [2], [5]-[7]. However, sustainability brings many challenges. Namely, managers are realizing that sustainability is becoming part of their business, but they fear the risk of

B. Grabot et al. (Eds.): APMS 2014, Part II, IFIP AICT 439, pp. 500-507 2014.

(C) IFIP International Federation for Information Processing 2014 
failing in dealing with it [8]. They have trouble understanding the incorporation of sustainability and the implications of their actions on long-term success [9]. Thus the difficulty is no longer whether to implement sustainability, but how [10]. Hence, as sustainability in enterprises still represents a conundrum, the aim of this article is to help managers of manufacturing enterprises understand, from an integrative perspective, the integration of sustainability, in order to enable them to exploit it as a new basis for long-term competitive advantage. Consequently, the following research questions are set: a) is sustainability in a manufacturing enterprise really a strategy and if it is so, which are its main characteristics, b) in which elements of the enterprise (strategic, tactical, operational) is sustainability applicable and what are the interrelations among them, c) what is the impact of the environment (legislature and market)? The results will be twofold: first depicting the main characteristics of sustainability as a strategy and secondly, through an integrative sustainability framework, identifying and assaying the main previously mentioned interrelations. Those two sets of results together represents the cornerstone of sustainability in manufacturing enterprises.

The value of this work for managers of manufacturing enterprises lies in helping them optimize their market position by using sustainability and to optimize its management. As for theory, it offers the first integrative framework for sustainability as a strategy for a manufacturing enterprise, taking into account the concept of fit. The article goes as following. After the literature review, the main definitions of the term "strategy" are assayed and applied on the concept of sustainability. In the next step, the main results are synthesized into an integrative framework.

\section{Literature Review}

Following the concept of sustainability science [11], this article is per se transdisciplinary, gathering the main pillars steaming from manufacturing, sustainability and strategy. Sustainable development goes back to Agenda 21 [12], an important policy document for sustainable development that was adopted at the Rio World Summit in 1992. Sustainability has many definitions, though the most famous is probably from Brundtland's report [13]: “... the ability to meet the needs of the present without compromising the ability of future generations to meet their own needs". Though there are many other definitions of suitability, the framework of the TBL [4] is chosen to work with in this article, as it is depicting the economic, social and environmental aspect of sustainability. Regardless of its high-level principal, sustainability can still be monitored, assessed and reported. An organization's performance in the wider context of sustainability is presented via reporting, using e.g. GRIG4 reporting guidelines. Another possibility to identify in more detail relevant elements of sustainability is to use a priority matrix [14]. Nonetheless, sustainability comes down to subjective rating, as the criteria and their indicators are mostly chosen and calculated based on opinion of experts, although much more exact techniques are also employed in the context of environmental sustainability like the Life Cycle Assessment technique [15]. 
Sustainability on the enterprise level is most often referred to as corporate sustainability. According to the Dow Jones Sustainability Index - it is a business approach that creates long-term shareholder value [9]. Interestingly sustainability within an enterprise seems to enable an early-mover advantage in international markets [16] or should even go as far as underpinning the current business models that are based on the idea to sell as much products as possible [17]. Sustainability has also been linked with the strategic management tool the Balanced Scored Board [18], resulting in a Sustainability Balanced Scorecard encompassing a perspective of the three pillars of sustainability [19]. Sustainability, the social part, has been also scrutinized in relation to manufacturing [20]. Regardless of its positive impact, sustainability is also criticized. It is argued that the concept is useless because it cannot be adequately defined [21] or that the term "sustainable development" is oxymoronic; how can something develop if it is to remain the same (i.e. "sustainable")? [22]. As identified, sustainability represents a high-level guidance that is certainly useful to some extent, however do not meet the rigid requirements to fully operationalize sustainable development in all the levels of the enterprise integrally, while taking into account the specificities of a manufacturing enterprise.

\section{$3 \quad$ Methodology}

This article conceptualizes the strategy of sustainability within a manufacturing enterprise. The dependent variable is long-term competitive advantage of a manufacturing enterprise. The independent variable is the strategy of sustainability. In this context, it is first delved if sustainability can even be considered as a strategy, by benchmarking it against the most renowned definitions of this term. Basing the conceptualization of the strategy of sustainability on rigid criteria in intermediate steps, it allow us to avoid the "problem of demarcation"; thus the article draws on Karl Popper's philosophy and onto its "falsificationism", claiming that "a hypothesis is scientific if and only if it has the potential to be refuted by some possible observation" [23]. In the spirit of this philosophy, we included strict criteria enabling us to critically refute the propositions made in this article.

\section{$4 \quad$ Model Development}

In order to identify the cornerstones of the strategy of sustainability for a manufacturing enterprise, the following conceptualization steps are followed. First, in order to position with validity sustainability into a manufacturing enterprise, it has to be reviewed if it can be treated as a strategy and what are its main characteristics. To scrutinize this, the main definitions of strategy are assayed, from which its most relevant characteristics are then derived, representing the next step. Finally, based on the results, an integrative framework depicting all the main interrelations relevant for the strategy of sustainability is designed.

Sustainability has already in some cases been recognized as a strategy [24], [25], in some cases as a perspective of a strategy [19]. The need for its management has been 
also widely acknowledged at different levels of the enterprise [26], [27]. The first definition of strategy is presented according to Porter [28], stating that strategy is the creation of a unique and valuable position, the way a firm chooses activities that differ from those of the competitors. If sustainability is able to create such position and choose differently its activities, it can be seen as a strategy. In addition, it would mean that it does not have only to position itself with a unique and/or valuable position, but it also has to relate this position to some operations within the enterprise. Namely, Porter [29] defines operational effectiveness and the choice of strategic positioning essential for a performance on the longer term. According to the second definition from Quinn [30], strategy is: "The pattern or plan that integrates an organization's major goals, policies, and action sequences into a cohesive whole." This would indicate sustainability to be a viable strategy that has to encompass the enterprise as a cohesive whole, thus indicating the urge for an internal fit. The concept of fit has been viewed as an internal consistency among key strategic decisions or the alignment between strategic choices and critical contingencies with the environment (external) [31], being essential for long-term success [32]. The third definition of strategy defines it as the pattern of decisions that determines and reveals its objectives and produces the principal policies and plans for achieving those goals. It also defines the range of business the company is to pursue, the kind of economic and human organization it intends to be, and the nature of the contributions to various stakeholders [33]. Such patterns and principal policies can also represent the integration of sustainability into the enterprise. According to this definition of strategy, priorities from the economic and human perspectives have to be assumed, as also to which stakeholders and to what extent the strategy should take into account those elements. Finally, according to Barney [34] "a good strategy ... neutralizes threats and exploits opportunities while capitalizing on strengths and avoiding or fixing weaknesses." This would indicate that sustainability within a manufacturing enterprise should be applied selectively, depending at least of the environment (legislative and market) and the relative position of the manufacturing enterprise itself. Hence, this means that sustainability is a viable strategy only when it presents itself as an opportunity to be exploited or as a threat that can be converted into an opportunity. However each business strategy is unique [35], therefore contingent upon many factors.

\subsection{The Cornerstones of the Strategy of Sustainability}

In the previous section, the main characteristics of a strategy in general were presented. In this subsection, four main characteristics are chosen, from which the main characteristics of sustainability strategy are derived. Afterwards the integrative framework for sustainability is depicted. Those two results constitute the cornerstone of sustainability for a manufacturing enterprise. The four main characteristics are the following (note: after each characteristic that is listed, it is then explained how it relates to sustainability).

First strategic characteristic. A strategy enables the manufacturing enterprise to position itself with a unique and/or valuable proposition [28], [36]. Sustainability can enable to change the strategic positioning of an enterprise (e.g. accessing a new 
customer segment). This positioning depends on the internal as well as on the external context, which is the market (i.e. industry, competition, trends etc.), and the legislative environment that is defining among others incentives for sustainability in manufacturing. Therefore, the positioning of a manufacturing enterprise based on the strategy of sustainability is contingent upon external context, which are the market and the legislative environment (see Fig. 1).

Second strategic characteristic. A strategy neutralizes threats and exploits opportunities while capitalizing on strengths and avoiding or fixing weaknesses [34]. Hence, the strategy of sustainability per se can represent itself as an opportunity or as a threat, thus how sustainability is perceived by an enterprise is contingent upon multiple factors. In a supportive environment for sustainability, moreover a supportive legislative (e.g. incentives for environment and social inclusiveness) and a supportive business environment (e.g. consumers are willing to pay a premium for sustainability related product-services), sustainability can represent a threat or an opportunity. Instances of both presented. Firstly, it represents a threat to the focal enterprise, if it cannot take advantage of the opportunities arising from the environment, while its competitors can. For instance, the focal enterprise has to close down its production plant due to a $\mathrm{CO}_{2}$ emission excess or cannot take advantage of development funds related to sustainability activities or cannot satisfy the new consumer trends, while its competitor can. However, secondly, if the focal enterprise has the internal capabilities to deploy the strategy of sustainability throughout its value chain and thus take advantage of the opportunities arising from such environment, then sustainability presents itself as an opportunity. It is even greater, if its competitors, on the other hand, are not able to take advantage of them. This would indicate that the focal enterprise is deploying a new basis for their long-term competitive advantage. Thirdly, if the focal enterprise intends to take advantage of the opportunities arising from sustainability, but it has assessed poorly its own internal capabilities for deploying such a complex strategy, than this strategy is seen as a threat. The application of such strategy would then impede the growth of its long-term competitive advantage. This case can be classified as a threat and not a weakness, because the sustainability strategy arise from the environment and not from the enterprise, however, it is also true that is transforming itself into a weakness after its integration.

Third strategic characteristic. After positioning itself in relation to sustainability, the manufacturing enterprise must choose activities that differ from the competitors and relate them to the newly chosen position [28]. Based on the strategy of sustainability, the enterprise must define its priorities in sustainability. They have to arise from the strategy and reflect onto the operations, for which the adequate manufacturing tactics have to be chosen.

Forth strategic characteristic. In order to be able to align the strategy with its tactics and operations on one hand and to align them with the environment afterwards, managers must encompass the enterprise as a cohesive whole, while indicating the urge for an internal fit [30]. Thus, two fits must exist. One that aligns the strategy with the tactical and operational level and the second that aligns the internal strategy with the environment. The former fit is essential, because according to a strategy of sustainability, specific tactics and operations have to be chosen and well aligned. It means, for 


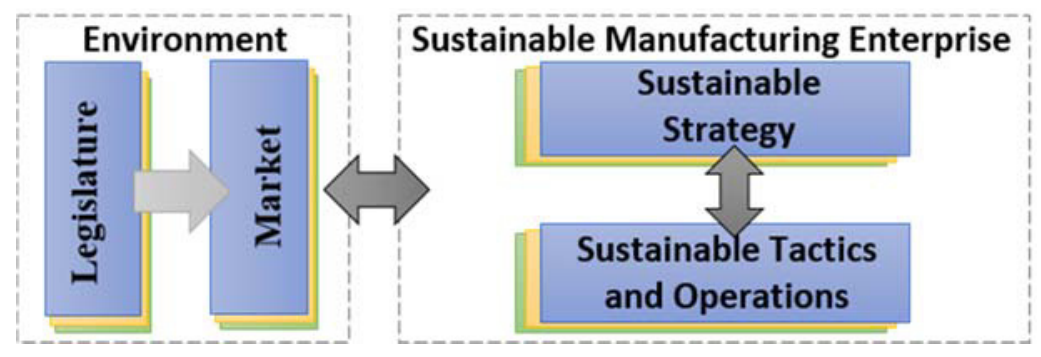

Fig. 1.The Strategy of Sustainability - fit and positioning

example, that if at the operational level a production line is optimized in terms of energy efficiency, also sustainability related improvements should be undertaken at the tactical level (e.g. product-services for sustainable consumption) as also should be aligned with the strategy. Only at the point when the two fits exist (internal and with the environment), a manufacturing enterprise can be seen as an optimized sustainable system. Otherwise, inefficiencies and opportunity costs arise, that in turn does not increase maximally its long-term competitive advantage. As for the second fit, the one between the enterprise and the environment is also crucial. Namely, if the legislative and business environments are not supportive towards the application of sustainability in manufacturing, which is the case for countries where industrialization has just begun or is still undergoing, then the strategy of sustainability for an enterprise in such an environment has no meaning. It can even become a threat, if the focal enterprise invests considerable amounts of resources into implementing sustainability, while no new business opportunities open up due to this investment.

The integrative model for sustainability of manufacturing is depicted on Figure 1. One component is the environment, constituted by the legislation and market, while the second segment is the enterprise. It has three main sub-segments, commencing with the strategy, going down to tactics and operations that are critical for manufacturing, while all are supported and performed by managerial processes. Each element is made of three layers, representing the TBL. Furthermore, the two fits can be seen with the two darker arrows, one among internal elements in the enterprise (strategy, tactics, operations) and the second between the enterprise and the environment. In the next research steps, it should be identified what exactly constitutes a sustainability strategy, to go another step closer to operationalize sustainability in an enterprise.

\section{Conclusion}

Sustainability through the perspective of a manager in a manufacturing enterprise was delved. In order to do so, it was first assayed if sustainability was a viable strategy for manufacturers, by leaning on the most renowned definition of the term "strategy". After confirmation, the key characteristics of the strategy of sustainability were derived. During the analysis, it was identified that sustainability is omnipresent in the enterprise as well as in the environment. Hence, managers must manage the strategy of sustainability integrally, taking into account all of its components within the enter- 
prise (strategy, tactics, operations and management), the fit among them, as also the fit between the enterprise and its environment (legislature and market).

Managing those complex and dynamic interrelations, while leaning on the key characteristics of the strategy of sustainability formed the cornerstone of sustainability strategy in manufacturing enterprise. Nonetheless, sustainability strategy is not a standalone strategy, but represents an additional basis for increasing the long-term competitive advantage. As it quite complex to manage, it is hence also very hard to imitate it, consequently being able to sustain such competitive advantage for a longer time, making the strategy of sustainability a sustainable one for a manufacturing enterprise.

Acknowledgement. This work has been partly funded by the European Commission through the FoF-ICT Project MSEE: Manufacturing SErvice Ecosystem (No. 284860). The authors wish to acknowledge the European Commission.

\section{References}

1. "Global Agenda Council on Advanced Manufacturing 2012-2014,". World Economic Forum (2012)

2. Dyllick, T., Hockerts, K.: Beyond the business case for corporate sustainability. Bus. Strateg. Environ. 11(2), 130-141 (2002)

3. Gladwin, T.N., Kennelly, J.J., Krause, T.-S.: Shifting paradigms for sustainable development: Implications for management theory and research. Acad. Manag. Rev. 20(4), 874-907 (1995)

4. Elkington, J.: Partnerships from cannibals with forks: The triple bottom line of $21 \mathrm{st}-$ century business. Environ. Qual. Manag. 8(1), 37-51 (1998)

5. Michael, B., Gross, R.: Running business like a government in the new economy: lessons for organizational design and corporate governance. Corp. Gov. 4(3), 32-46 (2004)

6. Salzmann, O., Ionescu-somers, A., Steger, U.: The Business Case for Corporate Sustainability: Literature Review and Research Options. Eur. Manag. J. 23(1), 27-36 (2005)

7. Valente, M.: Theorizing Firm Adoption of Sustaincentrism. Organ. Stud. 33(4), 563-591 (2012)

8. Berns, M., Townend, A., Khayat, Z., Balagopal, B., Reeves, M., Hopkins, M.S., Kruschwitz, N.: The business of sustainability: what it means to managers now. MIT Sloan Manag. Rev. 51(1), 20-26 (2009)

9. Epstein, M.J., Roy, M.-J.: Making the business case for sustainability. J. Corp. Citizsh. 2003(9), 79-96 (2003)

10. Epstein, M.J., Roy, M.-J.: Sustainability in action: Identifying and measuring the key performance drivers. Long Range Plann. 34(5), 585-604 (2001)

11. Clark, W.C., Dickson, N.M.: Sustainability science: the emerging research program. Proc. Natl. Acad. Sci. 100(14), 8059-8061 (2003)

12. Sitarz, D.: Agenda 21: The earth summit strategy to save our planet. Earth Press (1993)

13. Brundtland, G.H.: World commission on environment and development. Our Common Futur., 8-9 (1987)

14. Bordt, M.: OECD Sustainable Manufacturing Toolkit. Sustain. US Compet. Summit, US Dep. Commer., vol. 8 (2009) 
15. Ibáñez-Forés, V., Bovea, M.D., Pérez-Belis, V.: A holistic review of applied methodologies for assessing and selecting the optimal technological alternative from a sustainability perspective. J. Clean. Prod. 70, 259-281 (2014)

16. Porter, M.E., der Linde, C.: Green and competitive: ending the stalemate. Harv. Bus. Rev. 73(5), 120-134 (1995)

17. Garetti, M., Taisch, M.: Sustainable manufacturing: trends and research challenges. Prod. Plan. Control 23(2-3), 83-104 (2012)

18. Kaplan, R.S., Norton, D.P.: Linking the balanced scorecard to strategy. Calif. Manage. Rev. 39(1) (1996)

19. Figge, F., Hahn, T., Schaltegger, S., Wagner, M.: The Sustainability Balanced Scorecard linking sustainability management to business strategy. Bus. Strateg. Environ. 11(5), 269-284 (2002)

20. Fantini, P., Taisch, M., Palasciano, C.: Social Sustainability: Perspectives on the Role of Manufacturing. In: Prabhu, V., Taisch, M., Kiritsis, D. (eds.) APMS 2013, Part I. IFIP AICT, vol. 414, pp. 62-69. Springer, Heidelberg (2013)

21. Costanza, R., Patten, B.C.: Defining and predicting sustainability. Ecol. Econ. 15(3), 193-196 (1995)

22. White, M.A.: Sustainability: I know it when I see it. Ecol. Econ. 86, 213-217 (2013)

23. Godfrey-Smith, P.: An introduction to the philosophy of science: Theory and reality. University of Chicago Press, Chicago (2003)

24. Epstein, M.J., Wisner, P.S.: Using a Balanced Scorecard to Implement Sustainability. Environ. Qual. Manag. 11(2), 1-10 (2001)

25. Unruh, G.: The Sweet Spot of Sustainability Strategy. MIT Sloan Manag. Rev. 55(1), 15-20 (2013)

26. Asif, M., Searcy, C., Garvare, R., Ahmad, N.: Including sustainability in business excellence models. Total Qual. Manag. Bus. Excell. 22(7), 773-786 (2011)

27. Corbett, L.M.: Sustainable operations management: A typological approach. J. Ind. Eng. Manag. 2(1), 10-30 (2009)

28. Porter, M.E.: What is strategy? Publ. (November 1996)

29. Porter, M.E., Kramer, M.R.: The competitive advantage of corporate philanthropy. Harv. Bus. Rev. 80(12), 56-68 (2002)

30. Quinn, J.B.: Strategies for change: logical incrementalism. R.D. Irwin (1980)

31. Ensign, P.: The concept of fit in organizational research. Int. J. Organ. Theory Behav (Marcel Dekker) 4(3/4), 287 (2001)

32. Govindarajan, V.: Implementing competitive strategies at the business unit level: implications of matching managers to strategies. Strateg. Manag. J. 10(3), 251-269 (1989)

33. Foss, N.J.: Resources, Firms, and Strategies: A Reader in the Resource-based Perspective. Oxford University Press (1997)

34. Barney, J.B.: Gaining and sustaining competitive advantage. Addison-Wesley, Reading (1997)

35. Rumelt, R.P.: Evaluating business strategy. In: Mintzb, H., Quinn, J.B., Ghoshal, S. (eds.) Strateg. Process. Revis., Ed. Prentice Hall Eur. (1998)

36. Mintzberg, H.: The Strategy Concept 1: Five P's for Strategy. U. of California (1987) 